\title{
Carbon and water cycle reconstructions across the Cretaceous-Paleogene boundary in Saskatchewan, Canada, and implications for bulk carbon interpretations of mass extinctions
}

\author{
R.D. BOURQUE ${ }^{1 *}$, P. DOUGLAS ${ }^{1}$, H.C. LARSSON ${ }^{2}$
}

${ }^{1}$ Department of Earth and Planetary Sciences, McGill University, 3450 University Street H3A 0E8, Montreal, Quebec, Canada [robert.bourque@mail.mcgill.ca, peter.douglas@mcgill.ca]

${ }^{2}$ Redpath Museum, McGill University, 859 Sherbrooke Street West H3A 0C4, Montreal, Quebec, Canada [hans.ce.larsson@mcgill.ca]

The Cretaceous-Paleogene boundary (K-Pg) is Earth's most recent mass extinction event, but changes to terrestrial carbon and water cycling associated with this event remain uncertain. In this study we used plant wax hydrogen and carbon isotope analyses to investigate changes to water and carbon cycling across the boundary in fluvial sediments from western Canada.

Hydrogen and carbon isotope analyses of plant wax lipids were measured [1,2] in two sections in southern Saskatchewan, Canada. Results show that disturbances to the carbon and water cycles lasted less than 5,000 years. We infer precipitation isotope values between -95 and $-160 \%$, implying relatively depleted precipitation that is in agreement with estimates of water isotopic composition in the Western Interior Seaway. We also observe a longer-term enrichment in plant wax $\delta^{13} \mathrm{C}$, affecting both aquatic and terrestrial plants that spans the boundary.

We observed a boundary carbon isotope excursion (CIE) in terrestrial plant waxes $\left(\mathrm{C}_{29} \mathrm{n}\right.$-alkane), but not in bulk sediment organic matter (OM). We used plant wax $\delta^{13} \mathrm{C}$ values to estimate changes in the bulk carbon isotope record, assuming all sedimentary carbon was derived from aquatic and terrestrial plants. This analysis showed that shifting proportions of these plant groups, and differential $\delta^{13} \mathrm{C}$ trends between them, could have strong effects on bulk $\mathrm{OM} \delta^{13} \mathrm{C}$ that could obscure the CIE. This analysis suggests that bulk $\mathrm{OM} \delta^{13} \mathrm{C}$ records should be treated with caution, and should attempt to account for changes in OM sources.

[1] Diefendorf \& Freimuth (2017) Organic Geochemistry, 103, 1-21. [2] Sachse et al. (2012) Annual Review of Earth and Planetary Sciences, 40, 221-249. 